\title{
INUNDAÇÕES, DESENVOLVIMENTISMO E SUSTENTABILIDADE URBANA: UMA ANÁLISE A PARTIR DAS ORIGENS NATURAIS E ANTRÓPICAS DOS DESASTRES AMBIENTAIS
}

\author{
Frederico Thaddeu Pedroso ${ }^{1}$ \\ Jerônimo Siqueira Tybush ${ }^{2}$
}

\begin{abstract}
Resumo: Milhares de brasileiros são vítimas de desastres ambientais de origem hidrológica. Objetivando analisar a ampliação da noção de sustentabilidade ao estudar as inundações urbanas, a presente pesquisa parte do seguinte problema: considerando a evolução e o desenvolvimentismo histórico dos centros urbanos brasileiro, em que medida as inundações urbanas possuem origens e agravantes antrópicas e, em caso afirmativo, quais os limites e possibilidades de regulação jurídico-política por intermédio de Políticas Públicas e da Legislação Ambiental Brasileira? A metodologia obedece ao quadrinômio Teoria de Base, Abordagem, Procedimento e Técnica. Ao final, foi possível identificar causas antrópicas do desastre.
\end{abstract}

Palavras-Chave: Complexidade; Desenvolvimento Urbano; Inundações Urbanas; Sustentabilidade; Vulnerabilidades.

\section{URBAN FLOODS, CITIES DEVELOPMENTS AND URBAN SUSTAINABILITY: NATURAL AND ANTHROPICS ORIGINS OF ENVIRONMENTAL DISASTERS}

\begin{abstract}
Thousands of Brazilians are victims of environmental disasters from hydrological origin. Aiming to analyze the notion of sustainability studying urban floods, this research starts from the following problem: considering the evolution and historical developmentalism of brazilian urban centers, what urban floods have anthropogenic origins and aggravations and, if so, what are the limits and possibilities of juridic-political regulation through Public Policies and local environmental legislation? The methodology complies with the Basic Theory, Approach, Procedure and Technique quadrinomial. In the end, it was possible to identify anthropogenic causes of the disaster.
\end{abstract}

Keywords: Complexity; Sustainability; Urban Development; Urban Floods; Vulnerabilities.

\footnotetext{
1 Mestrando no Programa de Pós-Graduação em Direito da Universidade Federal de Santa Maria (PPGD/UFSM). Bacharel em Direito pela Universidade Franciscana (UFN). Pesquisador do grupo de pesquisa em Direitos da Sociobiodiversidade (GPDS), vinculado à Universidade Federal de Santa Maria (UFSM). Associado no Conselho Nacional de Pesquisa e Pós-Graduação em Direito. Advogado. *E-mail: frederico.pedroso@acad.ufsm.br.

${ }^{2}$ Doutor em Ciências Humanas pela Universidade Federal de Santa Catarina (UFSC). Mestre em Direito Público pela Universidade do Vale do Rio dos Sinos (UNISINOS). Graduado em Direito pela Universidade de Santa Cruz do Sul (UNISC). Professor titular no Departamento de Direito da Universidade Federal de Santa Maria (UFSM). Professor do Programa de Pós-Graduação em Direito (PPGD/UFSM). Professor do Programa de PósGraduação em Tecnologias Educacionais em Rede (PPGTER/UFSM). Pesquisador e Líder do Grupo de Pesquisa em Direito da Sociobiodiversidade (GPDS/UFSM). Atualmente é Pró-Reitor Adjunto e Coordenador de Planejamento Acadêmico da Pró-Reitoria de Graduação da UFSM. Membro da Diretoria do CONPEDI Gestão 2020-2023.*E-mail: jeronimotybusch@ufsm.br.
} 


\section{INTRODUÇÃO}

Os desastres ambientais hidrológicos possuem um grau elevado de ocorrência em solo brasileiro. Apesar de serem considerados fenômenos naturais, existe uma inegável conexão entre tais eventos e fatores e ações antrópicas (mudanças climáticas, má gestão urbana-ambiental, omissões estatais, estilo de vida da população etc.). Aludida conexão acaba por agravar os inúmeros desequilíbrios causados por este tipo de desastre.

Visando a obtenção de uma alternativa teórica hábil a ampliar a noção de sustentabilidade ao estudar um desastre que em um primeiro momento pode parecer ter causas unicamente naturais, a presente pesquisa parte do seguinte problema: considerando a evolução e o desenvolvimentismo histórico dos centros urbanos brasileiro, em que medida as inundações

urbanas possuem origens e agravantes antrópicas e, em caso afirmativo, quais os limites e possibilidades de regulação jurídico-política por intermédio de Políticas Públicas e da Legislação Ambiental Brasileira? Partindo do questionamento, o artigo objetiva examinar o desenvolvimentismo e os processos da urbanização brasileira e os desastres de origem hidrológica, a fim de evidenciar vulnerabilidades socioambientais-urbanas e assim revelar as (in) suficiências da gestão local dos riscos e dos danos catastróficos.

Para o enfrentamento do tema e problema propostos, o método científico a ser empregado obedecerá ao quadrinômio Teoria de Base, Abordagem, Procedimento e Técnica. Como Teoria de Base, optou-se por autores filiados a Teoria Jurídica denominada como pragmático-sistêmica e que exploram as pluridimensões da sustentabilidade, como Jerônimo Tybush. A abordagem utilizada é a sistêmico-complexa, que, aliada a Teoria de Base, propicia uma base comunicacional entre áreas do saber, bem como uma análise de dados em harmonia com os elementos da complexidade. O procedimento calca-se na pesquisa bibliográfica e na documental, a partir das técnicas de fichamentos, resumos estendidos e elaboração de gráficos e tabelas.

\section{O DESENVOLVIMENTISMO E A EVOLUÇÃO DAS CIDADES NO BRASIL}

A importância das redes urbanas e das cidades remetem ao período colonial, fazendo parte da história do Brasil desde o seu "descobrimento". Os (poucos) centros urbanos da 
época representavam palcos estruturados construídos para proporcionar mecanismos de exercício do poder (político, administrativo e econômico) pela Coroa, para que a exploração econômica do território fosse facilitada (SOUSA, 2005) - e o poder disciplinar mais facilmente exercido sobre os agentes envolvidos nesses processos.

Nesse sentido, o referido contexto socioeconômico (relação Portugal x colônia) não favorecia a formação de redes urbanas, que, quando formadas, não se preocupavam com nada relacionado à sustentabilidade urbana. Na lição de Nestor Goulart Reis Filho (2000, p. 195), "não houve urbanização no país durante os primeiros anos desde a chegada dos portugueses, enquanto a economia predatória e extrativista foi a base das práticas territoriais. O sentido utilitarista, atribuído a natureza, predominava”. À época, o Brasil colonial representava um meio, uma retaguarda rural do mercado europeu. O país era tido como uma grande empresa rural-agrícola voltada para a exportação, e essa inclinação guiou a ordenação do território urbano (FUJITA, 2008).

A transição para o Brasil Império (1822-1889) veio acompanhada de transformações socioeconômicas que influenciaram a ordenação do território local. A vinda da corte portuguesa, por exemplo, causou um incremento qualitativo nas cidades já existentes até então (FUJITA, 2008). Lenta e paulatinamente, a importância da dimensão territorial começava a ganhar destaque. Apesar de o planejamento nacional e o desenvolvimento urbano terem ganhado força somente a partir do século XX, no período Imperial já começava a surgir uma perspectiva de território nacional, ainda que discretamente (FUJITA, 2008).

Foi no decorrer do século XIX que mudanças urbanas relevantes começaram a ganhar força. Aumento demográfico, propriedade privada institucionalizada, transporte, iluminação, abastecimento de água, enfim, a infraestrutura urbana nos moldes da que conhecemos hoje começou a dar os seus primeiros passos no Brasil (MAIA, 2014).

Aliado a isso, em escala global, a ideia de Estado Moderno difundia-se por diversos países, o que também influenciou a organização política-administrativa-territorial local. A ideia de "Estado Nação" - e do constitucionalismo inaugurado pelo sistema jurídico francês propagada pelos alicerces vanguardistas oriundos da Revolução Francesas (1789), que possui como essência a proteção ao acúmulo de riqueza e de terras (propriedade privada), adentrou de forma significativa no Brasil Imperial e guiou a evolução do desenvolvimento urbano durante o período (MAIA, 2014). Horacio Capel (2002, p. 189) discorre sobre a evolução urbana brasileira durante o século XIX: 


\begin{abstract}
Adoptaron asimismo un plano ortogonal las nuevas creaciones urbanas en el Brasil del siglo XIX, que se fueron fundando en relación con los avances de la colonización hacia el interior y con la creación de nuevas estructuras políticas. La ideología positivista de una parte de la burguesía y de la clase política brasileña, con la formación de algunos ingenieros en la École Polytéchnique de París, contribuye a la difusión de modelos. Para los ingenieros positivistas una gran ciudad debía modelarse bajo los principios de la ingeniería, la higiene y la economia social. Esas fundaciones tienen un plano ortogonal que era poco común en el Brasil colonial, excepto en Salvador, pero que ahora se aplica ampliamente, con una plaza central para la catedral y plazas secundarias insertas en el damero. Son los casos de Teresina (1851) y Aracaju (1855) fundadas como capitales provinciales ${ }^{3}$.
\end{abstract}

Neste contexto de desenvolvimento urbano que ocorreu a transição para o capitalismo no Brasil, iniciada com a revolução política-burguesa da virada do século XIX para o XX, que culminou na Proclamação da República, em 15 de novembro de 1889. Conforme a lição de João Rodrigo Araújo Santana (2013), a modernização advinda com o surgimento da forma republicana de Estado se operou a partir de bases equivocadas, de valores europeus, partindo da própria nação um certo desprezo para com o seu próprio povo. Ainda, a busca da "garantia a ordem social em meio a modernidade" se deu através de um forte conservadorismo, dos valores do patriarcado burguês, que enriquecia a partir do capitalismo moderno (essencialmente liberal, libertário) mas oferecia forte resistência na manutenção da pessoalidade, da cultura do favor, do senso de hierarquia, do individualismo e do familismo (SANTANA, 2013).

Apesar disso, a República foi fundada e institucionalizada a partir de dois fundamentos: progresso e civilização (FERREIRA, 2003). Todavia, o Brasil ainda era um país dependente e periférico. As transformações urbanas avançavam apenas em cidades destaque, como o Rio de Janeiro, que no histórico dia 15 de novembro de 1889 "anoiteceu como corte imperial e amanheceu como capital republicana" (FERREIRA, 2003, p. 5). Nesse sentido, na primeira metade do século XX, foram lançados diversos planos para evolução urbana da recém fundada república brasileira, objetivando a extensão das cidades, sistemas

\footnotetext{
${ }^{3}$ Em tradução nossa: "As novas criações no Brasil do século XIX adotaram um plano ortogonal que se foram fundando relacionados ao avanço da colonização no interior e com a criação de novas estruturas políticas. A ideologia positivista de uma parte da burguesia e da classe política brasileira, com a formação de alguns engenheiros na École Polytéchnique de Paris, contribuiu para a difusão do modelo. Para os engenheiros positivista uma grande cidade deveria ser modelada a partir de princípios da engenharia, higiene e economia social. Esses fundamentos possuem uma planta ortogonal que era pouco comum no Brasil colonial, exceto em Salvador, mas que agora se aplica deliberadamente, com uma praça central para a catedral e praças secundárias inseridas no tabuleiro de xadrez. São os casos de Teresina (1851) e Aracaju (1855), que foram fundadas como capitais provinciais".
} 
viários, articulação de bairros nas áreas urbanas e propostas de zoneamento (TOPAN, 2017). Mas sempre considerando (leia-se, privilegiando), o pensamento político-econômico das elites, que guiaram a produção das cidades a partir dos interesses voltados para a economia rural. Dessa forma, o desenvolvimento urbano evoluiu vinculado a propósitos econômicosmercantis (PIRES, 2004). A produção agrícola superava a industrial e o poder econômico ainda estava nas áreas rurais.

A partir da guinada dos rumos econômicos do país com o Estado Novo de Getúlio Vargas, a industrialização no Brasil começa a ganhar força, bem como o deslocamento da lógica urbano-social: do campo para as cidades. Nos anos 1940, o valor da produção industrial ganhava destaque, em que pese a população majoritariamente ainda permanecesse no campo (PIRES, 2004). Como consequência, o Estado começava a intervir no âmbito das atividades urbanas, atentando-se ao desenvolvimento industrial e municipal.

Consequentemente, a sociedade brasileira passou a se modernizar em um ritmo acelerado. Como marco central, a modernização possui a quebra de hegemonia da economia tipicamente agrária/agrícola que era desenvolvida até então. Paulatinamente, o processo de industrialização foi fomentado pelo Poder Público (MARTINE, 1990). Nesse sentido, houve um acelerado processo de urbanização no Brasil, que foi uma determinante estrutural da constituição da sociedade nacional moderna (DE BRITO, 2012). A desruralização da sociedade (êxodo rural) passou a ser progressiva e acelerada, para muito além do planejamento urbano que se tinha à época. Vejamos a lição de Ana Amélia Camarano e Ricardo Abramovay (1999, p. 8) acerca da migração rural-urbana durante o período:

A população rural brasileira atingiu seu máximo em 1970 com 41 milhões de habitantes, o que correspondia a $44 \%$ do total. Desde então o meio rural vem sofrendo um declínio populacional relativo e absoluto, chegando em $1996 \mathrm{com}$ um total de 33,8 milhões de habitantes, ou 22\% do total nacional. A redução da importância da população rural deve-se, fundamentalmente, aos movimentos migratórios. Observa-se, até 1980, um crescimento absoluto do saldo populacional que deixou as áreas rurais. Aproximadamente $40 \%$ da população que vivia nas áreas rurais no começo dos anos 70 migraram nessa década. O fluxo que deixou o campo nos anos 80 também foi expressivo: $1 / 3$ de todos os que viviam no meio rural em 1980 dali saiu durante o período, o que representou aproximadamente 13 milhões de pessoas. Entre 1990 e 1995 este movimento migratório superou os 5,5 milhões de habitantes. Isto significa que, se esta taxa persistisse durante toda a década, $28 \%$ da população rural que vivia no meio rural em 1990 terão mudado sua residência no ano 2000. 
Apesar das taxas relevantes de avanço da população urbana no Brasil, o processo de urbanização frenético do século XX não foi acompanhado das devidas cautelas. Não houve um planejamento socioespacial voltado à população brasileira. Um contraste significativo começou a ser evidenciado com a explosão urbana, em praticamente todas as cidades, independentemente da dimensão - megacidades, metrópoles ou cidades de médio e pequeno porte (PIRES, 2004, p. 7):

Disso resulta, no âmbito urbano, o novo perfil socioespacial que apresenta, de um lado, centralidades e áreas de qualidade de vida vinculadas a uma minoria e, do outro, periferias e áreas de padrões inadequados de habitualidade ocupados pela maior parte da população, o que estabelece uma tensão entre cidade de incluídos e cidades dos excluídos, em substituição àquela que se expressa pela relação urbanorural.

O fenômeno da urbanização nesses moldes, aliado a ideologia do ser urbano como "modelo" de civilidade, acarretou problemas graves em âmbito local no país. Para Carlos Walter Porto-Gonçalves (2012), o ocorrido no Brasil e em outros países periféricos (Sul Social) não foi um processo de urbanização, mas, sim, uma verdadeira desruralização que se deu a partir de um menosprezo a vida campesina ${ }^{4}$. É a partir daí que começam a surgir as aglomerações suburbanas (periferias), que, ao apresentarem vulnerabilidades sistêmicas, escancaram os limites do processo de urbanização brasileiro.

Nesse cenário, a formação das cidades brasileira mutou-se para uma produção de ambientes urbanos precários. Essa precariedade do contexto urbano acarreta severas vulnerabilidades, de ordem urbana, ambiental, econômica, social e política. O caos social das periferias brasileiras demonstra que, inquestionavelmente, a população urbana aumentou, mas inclusão social-urbana, não (PORTO-GONÇALVES, p. 10):

Ainda, nem mesmo a ideia do urbano enquanto artificialização da natureza se pode
alegar para esses aglomerados das periferias, na medida em que, até nesse sentido, a
população sente da maneira mais dramática a vulnerabilidade a doenças, as
enchentes e a desmoronamentos de encostas a que estão quotidianamente
submetidos. A natureza se faz presente mais como morte do que como vida nessas
novas configurações urbanas-e-suas-periferias. A violência é mais aberta
demonstração do quanto estamos longe de ter a mais elementar regra de civilidade
de um regime democrático, isto é, o convencimento pela palavra, pela argumentação

\footnotetext{
${ }^{4}$ Para Michel Foucault, os sujeitos se constituem a partir de discursos construídos historicamente pelas relações de poder dominantes. "A produção do discurso é ao mesmo tempo controlada, selecionada, organizada e redistribuída por certo número de procedimentos que têm por função conjurar seus poderes e perigos, dominar seu acontecimento aleatório, esquivar sua pesada e temível materialidade" (FOUCAULT, 2013, p. 9).
} 
e não pela força ou pela bala. $\mathrm{O}$ crescimento da população vivendo em cidades no mundo não tem sido acompanhado pela cidadania.

Foram sob estes alicerces históricos que se chegou ao resultado das cidades contemporâneas brasileiras - um resultado da evolução dos fenômenos expostos em linhas alhures (PEREIRA, 2018). A explosão urbana se intensificou a partir da segunda metade do século XX e hoje causa consequências sociais-ambientais-jurídicas nefastas a maior parcela de seus habitantes (mais pobres), o que não é um fenômeno apenas nacional ${ }^{5}$, diga-se de passagem. Na lição de Stephen Graham (2016, p. 50) “em 2007, metade dos 6,7 bilhões de pessoas do mundo podia ser classificada como citadina. De uma hora para outra, o Homo Sapiens tinha se tornado uma espécie predominantemente urbana".

A essência das cidades modernas brasileiras, que na atualidade possuem forte dependência com redes altamente complexas (como a de infraestrutura, água, alimentos, energia) pode ser visualizada nos nuances sistêmicos (problemáticos) que esta pesquisa se propõe a investigar. Ainda conforme Carlos Walter Porto-Gonçalves (p. 11):

\begin{abstract}
Talvez um dos maiores desafios que se apresentam diante de nós é o de reconhecer (e superar) esse caráter racista que atravessa todo o processo de globalização desde os seus primórdios, em 1492, e que hoje se manifesta de modo agudo no quotidiano de populações que convivem mais proximamente, não só porque vivem lado a lado nas cidades-e-suas-periferias imediatas como, também, pela maior mobilidade das pessoas (migrações) e pelos meios de comunicação. O espaço geográfico onde vivemos nosso dia a dia abriga essa história por meio do seu hábitat e de seus habitantes, com as particularidades derivadas das lutas sociais, dos avanços e recuos nos processos de democratização que se desenvolvem de modo desigual pelo planeta. Na América Latina, por exemplo, a intensa desruralização e urbanoperiferização dos últimos 30-40 anos se fez, na maior parte dos países, sob regimes ditatoriais e, assim, longe de assimilar os movimentos sociais como legítimos protagonistas da invenção de práticas democráticas, criminalizava-os e marginalizava-os, mesmo quando contemplava suas reivindicações materialmente (saneamento, habitação, aumento de matrículas em escolas etc.).
\end{abstract}

Superada a introdução histórico-cultural do surgimento e estabelecimento dos centros urbanos no Brasil, a fim de evidenciar o modelo de desenvolvimento urbano concebido no país, passa-se a abordar a complexidade dos espaços urbanos e os contextos que se relacionam com as origens e causas do desastre objeto da investigação: as inundações urbanas. A partir disso, objetiva-se ampliar a noção de sustentabilidade para além dos

\footnotetext{
${ }^{5}$ Em que pese o objeto da pesquisa se detenha ao Brasil, problemas análogos podem ser vislumbrados em outros países, principalmente nos periféricos. Entre 1950 e 2005, a população urbana na América Latina e Caribe, por exemplo, passou de $41,9 \%$ para 77,6\%, com estimativas crescentes para os próximos anos (AVENDAÑO, 2006).
} 
aspectos ambientais-urbanos (naturais e sociais) de forma não-reducionista e em consonância com a metodologia empregada (teoria de base e abordagem).

\section{ESPAÇO URBANO E INUNDAÇÕES: UMA ABORDAGEM (SISTÊMICA- COMPLEXA) NÃO-REDUCIONISTA DO DESASTRE}

O Direito dos Desastre é um ramo ainda pouco explorado na ordem jurídica brasileira. Apesar de constantes, os desastres ainda carecem de normas e princípios que proporcionem uma maior segurança jurídica a toda sociedade. Em um contexto urbano, um desastre pode acarretar destruições patrimoniais de difícil reparação ou irreparáveis, podendo, inclusive, levar a óbito os moradores dos locais atingidos.

Segundo a Instrução Normativa $n^{\circ}$ 01, de 24 de agosto de 2012 (BRASIL, 2012), publicada pelo Ministério da Integração Nacional para detalhar com maior precisão a Lei $\mathrm{n}^{\circ}$ 12.608/2012 (BRASIL, 2012), desastre significa:

\footnotetext{
O resultado de eventos adversos, naturais ou provocados pelo homem sobre um cenário vulnerável, causando grave perturbação ao funcionamento de uma comunidade ou sociedade envolvendo extensivas perdas e danos humanos, materiais, econômicos ou ambientais, que excede a sua capacidade de lidar com o problema usando meios próprios.
}

Nesse sentido, as inundações urbanas são originadas a partir de um transbordamento das águas dos rios de seu leito natural de escoamento. Em razão deste fenômeno, um grande volume de água desses rios, exponencialmente aumentado pela alta das chuvas, invade áreas que a população utiliza para diversos fins, como moradia, transporte, comércio, entre outras atividades urbanas típicas (TUCCI, 1995).

Em caráter introdutório a construção teórica pretendida pelo presente capítulo e em face da divergência de termos utilizados para referir-se ao desastre ora estudado no Brasil, cumpre determinar a terminologia que será empregada ao longo de todo texto. Roberto Fabris Goerl e Mosato Kobiyama (2005, p. 3) esclarecem de forma didática como identificar uma enchente: "quando se coloca uma quantidade de água até sua máxima capacidade, diz-se que o copo está cheio. Esta situação também ocorre nos rios". Assim, quando o volume do rio se eleva até a altura de suas margens sem que ocorra o transbordamento para áreas adjacentes, se está diante de uma enchente - um movimento hidrológico consequente do curso natural 
d'água. Já as inundações urbanas ocorrem justamente quando o transbordamento desse (grande) volume de água se materializa, causando danos e/ou destruindo as ocupações das proximidades, ou até mesmo mais distantes, dependendo das especificidades do local (FERREIRA, 2019).

Considerando a perspectiva supramencionada, em um primeiro momento, as inundações urbanas podem parecer um acontecimento natural, eis que se originam a partir de um índice pluviométrico acima da média, que acaba por aumentar o volume das águas dos rios. Acontece que o aumento considerável no nível de chuvas na atualidade possui causas antrópicas ou mistas (LOURENÇO, 2007), sendo apontado como um efeito das mudanças climáticas causadas pelo aquecimento global, por exemplo (CARVALHO, 2019).

Registra-se que o objetivo da pesquisa passa longe de estabelecer uma crítica ou propor intervenções humanas no âmbito da geociência (BITAR, 2014). Os movimentos hidrológicos naturais e as enchentes dos rios não são suscetíveis de controle humano (FERREIRA, 2019). A pretensão científica proposta gravita em torno dos objetivos expostos em linhas alhures: oferecer elementos teóricos hábeis a contribuir com uma correta compreensão da capacidade da inundação urbana produzir danos considerando vulnerabilidades, riscos e resiliências (BITAR, 2014). Uma gestão urbana-ambiental das inundações urbanas que intencione evitar ou reduzir danos deve considerar essas noções pluridimensionais, naturais em consonância com as sociais.

Contextualizando o objeto da presente pesquisa com que foi exposto no primeiro capítulo, sabe-se que o desenvolvimento desenfreado das cidades nas últimas décadas foi pautado em uma falsa crença (inerente à modernidade) de que a civilidade se dá a partir da urbanização (LEFF, 2001). Com base nesta ideia (imposta) a sociedade passou a viver como se devesse ser urbanizada ${ }^{6}$, negligenciando por completo diversas dimensões da sustentabilidade que uma urbanização tão rápida e acentuada exige. Esta é uma das, senão a principal, causas explicativas da razão de as cidades gaúchas que se desenvolveram às margens de rios sofrerem, cada vez mais, com o desastre inundação. Vejamos a reflexão de Carlos Walter Porto-Gonçalves (2012, p. 183):

\footnotetext{
${ }^{6}$ No curso Segurança, Território e População, o filósofo Michel Foucault aborda a divisão do espaço a partir da análise dos mecanismos de biopoder. Para o autor, existe um projeto de técnica política destinada ao meio (cidade) e que funciona justamente em razão disso. Para o francês, na modernidade, o meio se torna determinante da própria natureza humana: "Uma multiplicidade de indivíduos que são e que só existem profunda, essencial, biologicamente ligados à materialidade dentro da qual existem” (FOUCAULT, 2008, p. 28).
} 


\begin{abstract}
A ideologia urbana como "modelo de civilidade" não corresponde à realidade cotidiana onde está $70 \%$ da população urbana no planeta. Dos quase 3 bilhões de urbanos no mundo, cerca de 924 milhões estão em favelas, sendo que dessa população favelada, 94\% estão na África, na Ásia, na América Latina e Oceania (...) $\mathrm{Na}$ verdade, a extensão territorial dessas aglomerações suburbanas - aqui sinônimo de subhumanas - ensejou a expressão periferia (...) As populações dessas periferias, além da enorme vulnerabilidade ao risco de causa imediata natural - chuvas, enchentes, furacões - vivem um ambiente de insegurança generalizado.
\end{abstract}

Neste contexto, destaca-se a lição do sociólogo Ulrich Beck (1992), o qual entende que as mudanças climáticas atingem a sociedade (os poluidores em larga escala e os cidadãos comuns) de forma injusta e desproporcional. O teórico alemão buscou definir um marco teórico-sociológico renovado a partir da transição da sociedade industrial para a atual, que denomina como global e de risco. A proposta de Ulrich Beck propõe modos de lidar com os riscos considerando as incertezas, as certezas contraditórias, as indeterminações, e os valores diferentes a respeito das sociedades que pretendemos (GUIVANT, 2001).

A conexão da práxis social contemporânea e a ambiental é fundamental para uma correta compreensão acerca da complexidade e o potencial danoso de uma inundação urbana. Em desastres dessa natureza (bem como nos mais variados), elementos diferentes se intersecionam, promovendo uma união entre a unidade e a multiplicidade (MORIN, 2000).

À vista dessa perspectiva, destaca-se o fato de que a degradação ambiental acontece e atinge, de modo desigual e injusto, locais e pessoas vulneráveis - populações sem recursos econômicos. Os pesquisadores que exploram esse tema denominaram a teoria de Justiça Ambiental. No Brasil, esses estudos ganham extrema relevância e aplicabilidade ante a realidade socioambiental do maior país da América Latina: "as gigantescas injustiças sociais brasileiras encobrem e naturalizam um conjunto de situações caracterizadas pela desigual distribuição de poder sobre a base material da vida social e do desenvolvimento" (ACSELRAD, 2004, p. 11). Nesse sentido, no país, os custos ambientais, sociais, econômicos e humanos das externalidades do crescimento e da produção de riquezas recaem de forma muito mais gravosa nos subúrbios e periferias urbanas do que em bairros nobres (BAKAN, 2008), supervalorizados pelo mercado imobiliário (principalmente pelo de natureza especulativa).

Esta é uma concepção aplicável à investigação ora proposta, considerando que nos centros urbanos brasileiros a parcela da população mais carente é comprimida a viver próxima às áreas mais degradadas do meio ambiente urbano (áreas menos disputadas pela especulação imobiliária), geralmente localizadas em zonas de risco, perto de lixões e de recursos hídricos 
contaminados. Dessa forma, os indivíduos e grupos sociais mais pobres e com menos acesso são, na prática, os mais expostos aos efeitos negativos da degradação ambiental e dos desastres dela decorrentes. A partir dessa perspectiva, considerar-se-á o desastre inundação urbana como um fenômeno social, em que as características determinadas como classe social, raça e localização possuem o potencial de influenciar o grau de exposição ao risco da comunidade e os danos por ela suportados (VERCHICK, 2019).

Para além dos aspectos meteorológicos (quanto de chuva caiu em determinado tempo sob determinada região), propõe-se uma discussão acerca das origens dos danos causados pela inundação, inserindo na investigação as questões sociais, políticas e econômicas (complementação do risco físico com o social) que poderiam passar desapercebidas em um olhar científico fragmentado, limitado à apenas uma área do conhecimento (CAPRA, 2006).

Neste cenário, a vulnerabilidade social dos indivíduos atingidos pelas inundações urbanas é relevante. Quanto a aspectos de vulnerabilidade e a distribuição desigual do risco ambiental, destaca-se a lição de Luís Marcelo Mendes e Jerônimo Siqueira Tybush Tybush (2017, p. 4):

\footnotetext{
A distribuição desigual do risco ambiental entre os indivíduos afeta de forma mais contundente os extratos sociais dos grupos historicamente vulnerabilizados, dentre os quais estão inclusos: as populações negras, os indígenas, os pobres e os trabalhadores. A repartição desigual do risco ecológico aumenta exponencialmente as condições de precarização da vida dos integrantes pertencentes aos grupos historicamente vulnerabilizados. Visto que estes indivíduos não estão inclusos no padrão social hegemônico pré-determinado pela lógica economicista do capital.
}

No Brasil, inundações, alagamentos e deslizamentos de encostas (natureza hidrometeorológica) têm ocorrido de forma cada vez mais frequentes. Pela Codificação Brasileira de Desastres (BRASIL, 2016), as inundações consistem na submersão de áreas fora dos limites normais de um curso de água em zonas que normalmente não se encontram submersas a partir de um transbordamento gradual, geralmente ocasionado por chuvas prolongadas. As enxurradas são um escoamento superficial de alta velocidade e energia, provocado por chuvas intensas e concentradas e são caracterizadas pela elevação súbita das vazões de determinadas drenagem e transbordamento brusco da colha fluvial, apresentando grande poder destrutivo. Já os alagamentos consistem na extrapolação da capacidade de escoamento de sistemas de drenagem urbana e consequente acúmulo de água em ruas, calçadas ou outras infraestruturas urbanas, em decorrência de precipitações. 
Estas classificações, de natureza eminentemente física, serão exploradas a partir da relação com outras vulnerabilidades, a fim de se investigar a capacidade de uma comunidade em retomar a vida e de resistir ao desastre objeto do estudo - o que resultará na perspectiva de resiliência, que engloba aspectos econômicos, sociais e jurídicos.

A vulnerabilidade física é um elemento inegavelmente presente nos desastres de natureza hidrológica e se refere à exposição física de uma comunidade a um risco derivado de sua localização, por exemplo, uma inundação, um terremoto ou um incêndio. Já a vulnerabilidade social refere-se à suscetibilidade dos grupos populacionais de uma comunidade aos impactos de um desastre. Com suporte nestes alicerces teóricos, chega-se a um corolário sumário: o desastre hidrometeorológico abordado não atinge a todos da mesma forma. A intersecção entre vulnerabilidade física e social cria a noção de risco que possibilita uma compreensão científica adequada dos impactos diferenciados dos desastres em determinados locais e em seus respectivos habitantes (CUTTER, 2011).

Diversos pesquisadores do Direito dos Desastres e áreas correlatas destacam que desastres puramente naturais não existem. Isso porque a combinação sistêmica entre fatores físicos e sociais são determinantes para os seus resultados danosos. A pesquisadora de desastres Susan Lynn Cutter (2011, p. 3), diretora do Instituto de Pesquisa de Riscos e Vulnerabilidades da Universidade da Carolina do Sul, Estados Unidos, propõe uma ciência da vulnerabilidade como abordagem para o estudo dos desastres ambientais:

Para isso é necessária uma abordagem integradora, que procure explicar as
complexas interações entre sistemas sociais, naturais e artificiais. Embora seja
importante entender os sistemas e processos naturais que dão origem aos riscos, não
é possível compreender completamente o impacto de tais processos ou
acontecimentos naturais, a menos que se examine a forma como esses sistemas
interagem com a sociedade. De igual modo, a ciência da vulnerabilidade examina as
interações entre sistemas sociais e sistemas e estruturas artificiais, como barragens,
diques, estruturas de proteção costeira ou redes urbanas e de transporte. A
vulnerabilidade tem origem no potencial de perda e de impacto negativo que estes
sistemas e/ou estruturas têm nas pessoas, ao falhar. Outro princípio fundamental da
ciência da vulnerabilidade é o requisito do conhecimento geoespacial e da
investigação com base nos locais. Todos os desastres são locais e as respostas
imediatas também o são. A ciência da vulnerabilidade ajuda a perceber como o
mesmo acontecimento pode produzir impactos muito diferentes nas zonas
envolventes.

Nesse mesmo sentido são as constatações de Neil Smith (2006) em pesquisa realizada para investigar as devastações decorrentes do furacão Katrina, que devastou boa parta da Costa do Golfo dos Estado Unidos em 2005, que deixou milhares de mortes e 
desabrigados e foi apontado como o mais destruidor da história americana (COUTINHO, 2007):

No Rio Grande do Sul, estado atingido recorrentemente por inundações urbanas ${ }^{7}$, verifica-se que os indivíduos despossuídos de poder econômico são os que efetivamente sofrem os efeitos imediatos do desastre que a presente pesquisa se propõe a investigar. Estas pessoas, vítimas da profunda segregação social materializada no âmago da sociedade brasileira, residem em áreas impróprias localizadas nas encostas dos rios, e vivem na margem ou abaixo da linha da pobreza. Neste sentido é a lição de Francielle Benini Agne Tybush (2019, p. 100), que relaciona vulnerabilidade social com o agravamento dos efeitos negativos dos desastres:

\begin{abstract}
Este cenário é agravado devido a vulnerabilidade física e social. Por exemplo, casas construídas em uma planície de inundação, que possuem apenas seu acesso por ruas não pavimentadas, podem ilustrar a vulnerabilidade nos dois sentidos. Os locais das residências demonstram que as estruturas frágeis estão no caminho das águas da enchente. E, as estradas que não estão pavimentadas, predispostas a destruições pelas águas, dificultarão o retorno dos moradores com os equipamentos necessários para a retomada, recuperação e reconstrução.
\end{abstract}

Quanto as nuances antrópicas inerentes as inundações, a questão urbana e sus corolários desenvolvimentistas aparecem como elementos alteradores do uso do solo e que conduzem a expansão das cidades sobre áreas impróprias de ocupação em razão de suas características geológicas e geomorfológicas (FERREIRA, 2019). Somado a isso, a geração de resíduos e as respectivas deficiências em sua gestão também influenciam os impactos das inundações em uma cidade - a disposição incorreta do lixo tem o potencial obstrutor das tubulações (drenagens urbanas), interferindo no curso da água e em sua capacidade de escoamento para o leito do curso original da água (FERREIRA, 2019).

Na lição de Adilson Pinheiro (2007, p. 96), não existem rios sem enchentes, mas, "quando o homem ultrapassa os limites das condições naturais do meio em que vive então as inundações passam a ser um problema social, econômico e/ou ambiental". Ainda, existe uma conexão entre o aumento dos índices pluviométricos e ações antrópicas típicas do processo urbano moderno:

\footnotetext{
${ }^{7}$ As três regiões hidrográficas (Rio Uruguai, Guaíba, do Litoral) do Estado possuem registros recentes de inundações urbanas (SECRETARIA DE PLANEJAMENTO, GOVERNANÇA E GESTÃO, 2020).
} 
Como se não fosse suficiente o impacto negativo, um estudo realizado pela Universidade de Campinas associa a impermeabilização do solo derivada da expansão da zona urbana ao aumento das taxas de precipitação pluviométricas, com o argumento de que o uso do cimento e do asfalto provoca a elevação da temperatura dos centros urbanos. As superfícies impermeáveis absorvem parte da energia solar, aumentando a temperatura ambiente, produzindo ilhas de calor nos centros urbanos, onde predominam esses materiais - que, também por sua cor escura, incrementam a emissão de radiação térmica, gerando calor. Esse aumento da temperatura, por sua vez, cria condições de movimento de ar ascendente que pode gerar aumento de precipitação (FERREIRA, 2019, p. 35).

Outro aspecto relevante e de certa forma determinante para a magnitude das inundações urbanas no território brasileiro são fatores econômicos e culturais que, combinados, culminam em uma inadequada visão ética do homem com a natureza (SHIVA, 2003). Na lição de Edward Osborne Wilson (1994, p. 335), os problemas ambientais possuem uma essência ética comum e exigem uma visão que "se estenda, simultaneamente, para os futuros próximos e distantes". Seguindo essa lógica, as inundações urbanas também possuem ligação com essa perspectiva ética-humana, estando conectadas com a degradação de áreas frágeis, desmatamento e ocupações em áreas de preservação ambiental (irregulares). Os ricos ecossistemas brasileiros, fortemente degradados a partir da percepção humana da natureza como mero objeto que lhe pertence e que pode ser utilizada ao bel prazer utilitarista ${ }^{8}$, acabam tendo a capacidade de prestar serviços ambientais de proteção contra as inundações urbanas ferida de morte (FERREIRA, 2019).

Neste contexto, a interferência humana nos ecossistemas naturais a partir da retirada da cobertura vegetal de refúgio para fauna e flora e a modificação da dinâmica do rio; o desmatamento em áreas de conservação; as intervenções antrópicas diretas nos leitos dos rios através de canalizações e retificações e das alterações do uso do solo a partir das construções urbanas e produções agropecuárias são fatores antrópicos que alteram a dinâmica dos ciclos hidrográficos e do desastre estudado como um todo, agravando o seu potencial destrutivo (FERREIRA, 2019). As ocupações de áreas inundáveis por diversos aspectos sociais (crucial para a incrementação de riscos para as inundações urbanas) também são elementos que integram a cadeia sistêmico-complexa das inundações urbanas.

\footnotetext{
${ }^{8} \mathrm{O}$ utilitarismo é uma perspectiva filosófica fundada pelo inglês Jeremy Bentham. A essência do utilitarismo é simples: o objetivo da moral é maximizar a felicidade. Assim, o utilitarismo leva em conta a soma dos benefícios de uma diretriz subtraído de todos os seus custos. Se o resultado produzir mais felicidade (prazer) do que dor (sofrimento), toda e qualquer decisão estaria justificada moralmente. Bentham acreditava que o princípio de utilidade poderia servir como base para reforma política enquanto ciência moral (SANDEL, 2020).
} 
Para além dos aspectos antrópicos relacionados à urbanização e a justiça ambiental mencionados, "a gestão da vida sobre a população enquanto população" como técnica política também deve ser considerada para uma compreensão adequada das inundações urbana, considerando a questão da naturalização da espécie humana dentro de um meio artificialmente produzido (cidades, territórios) como regra civilizatória (TYBUSH, 2011).

A perspectiva de biopolítica de Michel Foucault (2008) exposta na última fase de sua vida nas aulas ministradas no icônico Collége de France também consiste no pano de fundo teórico utilizado na análise crítica ao urbanismo moderno desenvolvida. É a partir de técnicas (bio) políticas destinadas ao meio, ao território, que as estruturas de poder que precedem o direito (TYBUSH, 2011) ganham forma e oferecem aos agentes detentores do poder técnicas para que "o corpo multidão se padronize e aceite mais facilmente os impactos ambientais e as decisões do Estado-corporação" (TYBUSH, 2011, p. 103). Considerar esses elementos que constituem quase que a natureza fundamental (metafísica) da política urbana se torna crucial em uma pesquisa sobre cidades, que nada mais são do que a expressão máxima da organização da sociedade enquanto sociedade (DOWBOR, 2017) - que decorre de decisões políticas.

Decisões políticas estas que se perpetuam no tempo independentemente dos representantes eleitos (e de suas localizações na régua política-ideológica ${ }^{9}$ ). No Brasil, é possível que se realizado um cálculo comparativo entre os gastos das municipalidades com a construção de pontes, túneis, asfaltos, estacionamentos etc. para automóveis com os gastos com saúde, educação, saneamento básico e prevenção/reparação urbana-ambiental se chegue a seguinte conclusão: os municípios governam mais para automóveis do que para pessoas (PORTO-GONÇALVES, 2012). Assim, é comum que as municipalidades gastem mais com na construção e na manutenção de ruas asfaltadas para automóveis do que com saúde, educação, saneamento básico e prevenção e reparação ambiental, por exemplo.

Tal cenário demonstra, em consonância com a seção 1, a existência de interferência antrópica, bem com a importância das decisões executivas e legislativas do Estado para a ocorrência e/ou agravamento das inundações urbanas. As vulnerabilidades urbanas (sociais) e a peculiaridades da gestão-urbana ambiental realizada em âmbito local influem na mesma

\footnotetext{
${ }^{9}$ A régua do espectro político é representação gráfico-didática que objetiva simplificar as complexas crenças políticas entre dois extremos: esquerda e direita. Entre os dois extremos (extrema esquerda e direita) há um caminho longo - social democrata, liberal democrata, neoliberal, conservador liberal (PRIOLI, 2021).
} 
proporção que os aspectos naturais (meteorológicos, geológicos etc.) e devem ser levados em conta.

\section{CONSIDERAÇÕES FINAIS}

A partir dos aspectos e perspectivas exploradas ao longo da pesquisa, foi possível tecer respostas à indagação inicialmente proposta. Como se viu, para uma correta compreensão e gestão dos riscos e danos do desastre investigado, faz-se necessária uma abordagem teórica de cunho científico multidisciplinar. Para tanto, a revisitação conceitual jurídico-político é urgente e necessita de aportes teóricos que possibilitem a construção e a difusão de alternativas diferenciadas.

Foi em vista disso que se desenvolveu a presente produção. Aliando aspectos políticos, jurídicos, sociais, culturais e econômicos, foi possível responder o questionamento proposto, à luz do pensamento sistêmico-complexo. Ao empregar a metodologia proposta, concluiu-se que uma gestão urbana-ambiental das cidades e das inundações urbanas que intencione evitar ou reduzir danos deve considerar essas noções pluridimensionais. As ciências naturais em consonância e comunicação com as Sociais.

A partir dessa perspectiva, a inundação urbana também pode ser inserida no âmbito dos fenômenos sociais e consequentemente ser tratada como um fato jurídico. Nesse sentido, a construção de novas alternativas políticas-jurídicas objetivando a sua tutela satisfatória se apresenta como crucial. Os fundamentos epistemológicos e metodológicos que alicerçam projetos e estratégias de políticas públicas urbanas devem estar conexão com a diversidade. $\mathrm{O}$ paradigma da complexidade, apontado como Stephen Hawking como "a ciência do século XXI", proporciona perspectivas renovadas e cada vez mais presentes nas pesquisas jurídicas.

\section{REFERÊNCIAS}

ACSELRAD, Henri; HERCULANO, Selene; PÁDUA, José Augusto (org.). Justiça ambiental e cidadania. Rio de Janeiro: Relume Dumará, Fundação Ford, 2004, p. 11. 
AVENDAÑO, Florencia Quesada. Imaginarios urbanos, espacio público y ciudad en América Latina. Pensar Iberoamérica: revista de cultura, v. 3, 2006.

BAKAN, Joel. A corporação: a busca patológica por lucro e poder. Tradução Camila Werner. São Paulo: Novo Conceito Editora, 2008.

BECK, Ulrich. Risk Society: Towards a New Modernity. Londres, Sage, 1992.

BITAR, Omar Yazbek. Cartas de suscetibilidade a movimentos gravitacionais de massa e inundações: nota técnica explicativa. IPT; CPRM, 2014.

BRASIL. Ministério da Integração Nacional. Instrução Normativa $n^{\circ} 01$, de 24 de agosto de 2012. Estabelece procedimentos e critérios para a decretação de situação de emergência ou estado de calamidade pública pelos municípios, estados e pelo distrito federal, e para o reconhecimento federal das situações de anormalidade decretadas pelos entes federativos e dá outras providências. Diário Oficial da União, 2012.

BRASIL. Instrução Normativa $n^{\circ}$ 2, de 20 de dezembro de 2016, anexo V. Disponível em: https://www.in.gov.br/materia/-/asset_publisher/Kujrw0TZC2Mb/content/id/24789597/do12016-12-22-instrucao-normativa-n-2-de-20-de-dezembro-de-2016--24789506. Acesso em 07 jul. 2021.

BRASIL. Subchefia para assuntos jurídicos. Lei $n^{\circ} 12.608$, de 10 de abril de 2012. Institui a Política Nacional de Proteção e Defesa Civil. Brasília. Disponível em:

http://www.planalto.gov.br/ccivil_03/_ato2011-2014/2012/lei/112608.htm. Acesso em: 14 jul. 2021.

CAMARANO, Ana Amélia; ABRAMOVAY, Ricardo. Exxodo rural, envelhecimento e masculinização no Brasil: panorama dos últimos 50 anos, 1999, p.8. Disponível em: http://repositorio.ipea.gov.br/bitstream/11058/2651/1/td_0621.pdf. Acesso em: 19 jun. 2021.

CAPEL, Horacio. La morfologia de las ciudades. I - Sociedad, cultura y paisaje urbano. Barcelona: Ediciones del Serbal, 2002, p. 189-190.

COUTINHO, Guilherme Castello Branco. O impacto causado pelo furacão Katrina na atividade turística no Bairro Francês, Nova Orleans-EUA. 2007. Monografia (Especialização em Turismo e Desenvolvimento Sustentável), Universidade de Brasília, Brasília, 2007. Disponível em: https://bdm.unb.br/handle/10483/190. Acesso em 05 jul. 2021.

CAPRA, Fritjof. A teia da vida: uma nova compreensão científica dos sistemas vivos. Tradução Newton Roberval Eichemberg. São Paulo: Cultrix, 2006.

CARVALHO, Délton Winter; SOUZA BARBOSA, Kelly. Litigância climática como estratégia jurisdicional ao aquecimento global antropogênico e mudanças climáticas. Revista de Direito Internacional, v. 16, n. 2, 2019. 
CUTTER, Susan Lynn. A ciência da vulnerabilidade: modelos, métodos e indicadores. Revista Crítica de Ciências Sociais, n. 93, p. 59-69, 2011. Disponível em: https://journals.openedition.org/rccs/165. Acesso em: 05 jul. 2021.

DE BRITO, Fausto Alves et al. A dinâmica do processo de urbanização no Brasil, 19402010. Cedeplar, Universidade Federal de Minas Gerais, 2012.

DOWBOR, Ladislau. O que é poder local. Brasiliense, 2017.

FERREIRA, Ximena Cardozo. Inundações Urbanas: gestão de riscos com foco na prevenção de danos. Rio de Janeiro: Lumen Juris, 2019.

FOUCAULT, Michel. A ordem do discurso: aula inaugural no Collège de France, pronunciada em 2 de dezembro de 1970. Tradução de Laura Fraga de Almeida Sampaio. $2^{a}$ ed. São Paulo: Edições Loyola, 2013.

FOUCAULT, Michel. O Nascimento da Biopolítica: curso dado no Collége de France, 19781979. Tradução Eduardo Brandão. São Paulo: Martins Fontes, 2008.

FOUCAULT, Michel. Segurança, território e população: curso dado no Collége de France, 1977-1978. Tradução Eduardo Brandão. São Paulo: Martins Fontes, 2008, p. 28

FUJITA, Camila. Dilema urbano-ambiental na formação do território brasileiro: desafios ao planejamento urbano no Brasil. Tese de Doutorado. Universidade de São Paulo (USP), 2008. Disponível em: https://www.teses.usp.br/teses/disponiveis/16/16135/tde-29032010162214/en.php. Acesso em: 09 jun. 2021.

GOERL, Roberto Fabris; KOBIYAMA, Masato. Considerações sobre as inundações no Brasil. XVI Simpósio Brasileiro de Recursos Hídricos, 3.

GRAHAM, Stephen. Cidades sitiadas: o novo urbanismo militar. Tradução Alyne Azuma. ${ }^{\text {a }}$ ed. São Paulo: Boitempo, 2016.

GUIVANT, Julia S. A teoria da sociedade de risco de Ulrich Beck: entre o diagnóstico e a profecia. Estudos Sociedade e Agricultura, 2001.

LEFF, Enrique. Saber Ambiental. Rio de Janeiro: Vozes, 2001.

LOURENÇO, Luciano. Riscos naturais, antrópicos e mistos. Territorium, n. 14, p. 109-113, 2007

MAIA, Doralice Sátyro. Normativas Urbanas no Brasil Imperial: A cidade e a Vida Urbana na Legislação Brasileira (1822-1850). Geo UERJ, v. 2, n. 25, p. 458-476, 2014. Disponível em: https://www.e-publicacoes.uerj.br/index.php/geouerj/article/view/14407. Acesso em: 14 jun. 2021.

MARTINE, George et al. A urbanização no Brasil: retrospectiva, componentes e perspectivas. In: IPEA/IPLAN. Desenvolvimento urbano. Rio de Janeiro, p. 99-158, 1990. 
MORIN, Edgar. Ciência com consciência. Rio de Janeiro: Bertrand, 2000.

NEVES, Margarida de Souza. Os cenários da república. O Brasil na virada do século XIX para o século XX. In: DELGADO, Lucília de Almeida Neves; FERREIRA, Jorge Luís (Orgs.). Brasil Republicano: Estado, sociedade civil e cultura política. O tempo do liberalismo excludente: da Proclamação da República à Revolução de 1930, 1ª ed. Rio de Janeiro: Civilização Brasileira, 2003, v.4, p. 14 a 44.

PEREIRA, Pedro Henrique Máximo. Territórios Panópticos: As cidades como campos de batalha. Anais do evento Cidade entre muros: do Alphaville à favela, 2018. Disponível em: Territorios-Panopticos-as-cidades-como-campos-de-batalha-Panoptic-Territories-cities-asbattlefields.pdf (researchgate.net). Acesso em 21 jun. 2021.

PIRES, Maria Coeli Simões. Os rumos do Direito Urbanístico no Brasil: avaliação histórica. Direito Izabela Hendrix, v. 4, n. 4, 2004.

PORTO-GONÇALVES, Carlos Walter. A Globalização da Natureza e a Natureza da Globalização. Rio de Janeiro: Civilização Brasileira, 2012.

PORTO-GONÇALVES, Carlos Walter. Para outras conexões rural-urbanas a reapropriação social da natureza. Disponível em:

http://www.eliomar.com.br/site/arquivostexto/conexoes_rural_urbana.pdf. Acesso em: 14 jul. 2021.

PRIOLI, Gabriela. Existe um estoque de problemas ancestrais que herdamos da escravidãoGPS Político com Ciro Gomes. Youtube, 15 mai. 2021. Disponível em:

https://www.youtube.com/watch?v=TjRBrrNTO0E. Acesso em: 14 jul. 2021.

REIS, Nestor Goulart Filho. Contribuição ao estudo da evolução urbana no Brasil 15001720. $2^{a}$. ed. São Paulo: Pini, 2000.

SANDEL, Michael J. Justiça: o que é fazer a coisa certa? Tradução: Heloísa Matias e Maria Alice Máximo. 33a ed., Rio de Janeiro: Civilização Brasileira, 2020.

SANTANA, João Rodrigo Araújo. A modernização do Rio de Janeiro nas crônicas de Olavo Bilac (1890-1908), 2013. Dissertação apresentada ao Programa de Pós-Graduação em

Ciências Sociais da Universidade Federal da Bahia. Disponível em: https://repositorio.ufba.br/ri/handle/ri/13697. Acesso em: 15 jun. 2021.

SANTOS, Rozely Ferreira. Vulnerabilidade Ambiental: desastre naturais ou induzidos? (org.). In: PINHEIRO, Adilson. Enchente e inundação. Brasília: Ministério do Meio Ambiente, 2007.

SOUSA, Avanete Pereira. Cidade, poder local e atividades econômicas: Bahia, século XVIII. Anais do XXIII Simpósio Nacional de História- ANPUH, Londrina, 2005. 
SECRETARIA DE PLANEJAMENTO, GOVERNANÇA E GESTÃO. Atlas socioeconômico Rio Grande do Sul. Disponível em: https://atlassocioeconomico.rs.gov.br/bacias-e-sub-baciashidrograficas. Acesso em: 07, jul. 2021.

SMITH, Neil. There's no such thing as a natural disaster. Understanding Katrina: perspectives from the social sciences, v. 11, 2006, p. 1. Disponível em: http://blogs.ubc.ca/naturalhazards/files/2016/03/Smith-There\%E2\%80\%99s-No-Such-Thingas-a-Natural-Disaster.pdf. Acesso em 05 jul. 2021.

SHIVA, Vandana. Monoculturas da mente: perspectivas da biodiversidade e da biotecnologia. Tradução Dinah de Abreu Azevedo. São Paulo: Gaia, 2003.

TOPAN, Nathalia Fernanda; RUSCHEL, Andressa Carolina. Urbanismo como reflexo do planeamento urbano no Brasil. Anais do $15^{\circ}$ Encontro Científico Cultural Interinstitucional e $1^{o}$ Encontro Internacional, 2017. Disponível em:

https://www.fag.edu.br/mvc/assets/pdfs/anais

2017/ANDRESSA\%20CAROLINA\%20RUSCHEL\%20(Prof)-ac.ruschel@hotmail.com3.pdf. Acesso em 19 jun. 2021.

TUCCI, Carlos Eduardo Morelli. Drenagem Urbana. Porto Alegre, Editora da Universidade ABRH, Edusp, 1995.

TYBUSH, Francielle Benini Agne. Vidas deslocadas: o caso Mariana-MG como modelo brasileiro para aplicação do direito dos desastres. Curitiba: Íthala, 2019, p. 100.

TYBUSH, Jerônimo Siqueira; MENDES, Luís Marcelo. A justiça ambiental como instrumento no combate a distribuição desigual do risco ecológico em sociedades ditas periféricas. In: Revista de Direito e Sustentabilidade. Maranhão, v.3, n.2, 2017, p. 4. Disponível em: https://www.indexlaw.org/index.php/revistards/article/view/2534. Acesso em: 01 jul. 2021.

TYBUSCH, Jerônimo Siqueira. Sustentabilidade multidimensional: elementos reflexivos na produção da técnica Jurídico-ambiental. 2011. Tese (doutorado) - Universidade Federal de Santa Catarina, Centro de Filosofia e Ciências Humanas. Programa de Pós-Graduação Interdisciplinar em Ciências Humanas. Disponível em: https://repositorio.ufsc.br/handle/123456789/103349. Acesso em 08 jul. 2021.

VERCHICK, Robert R. M. (In)Justiça dos Desastres: a geografia da capacidade humana. In: FARBER, Daniel A; CARVALHO, Délton Winter de (Orgs). Estudos aprofundados em Direito dos Desastres: interfaces comparadas. 2a. Ed. Curitiba: Appris, 2019.

WILSON, Edward Osborne. Diversidade da vida. São Paulo: Cia das Letras, 1994. 